\title{
La muerte del Ruiseñor, de Carlos Martín Briceño: espacio textual de confluencia entre la escritura autofictiva y la novela metafictiva
}

\section{La muerte del Ruiseñor, by Carlos Martín Briceño: textual space of confluence between self-fiction and the metafictive novel}

\author{
Carlos Vadillo Buenfil \\ Universidad Autónoma de Campeche \\ cjvadill@uacam.mx
}

Resumen: Este artículo analiza La muerte del Ruiseñor de Carlos Martín Briceńo como una autoficción biográfica con trazos metanovelescos, en suma, como una creación auto-metaficcional. El procedimiento compositivo de la novela parte de datos reales y verosímiles, un escritor que transmite sus rasgos identitarios a un autor que es protagonista de su historia imaginada. A este recurso se suman las confesiones íntimas y las preocupaciones del proceso escritural de la novela que el autor ficticio elabora sobre el trovador yucateco Guty Cárdenas, protagonista histórico que revela homologías con el novelista empírico y el novelista fingido del relato. Los mecanismos narrativos aludidos nos inducen a considerar la ópera prima del escritor meridano desde la perspectiva de la auto-metanovela. 
Palabras clave: autoficción, auto-metanovela, Carlos Martín Briceño, narrativa mexicana actual, hibridez textual.

Abstract: This article analyzes La muerte del Ruiseñor by Carlos Martín Briceño as a autofictional biography with metanovelesque traces, in short, as a self-metafictional creation. The compositional procedure of the novel is based on real and credible data, a writer who transmits his identity traits to an author who is the protagonist of his imagined story. To this resource are added the intimate confessions and concerns of the novel's writing process that the fictional author elaborates on the Yucatecan troubadour Guty Cárdenas, a historical protagonist who reveals homologies with the empirical novelist and the fictional novelist of the story. The aforementioned narrative mechanisms induce us to consider the debut of the Merida writer from the perspective of the auto-metanovela.

Keywords: Autofiction, Auto-metanovela, Carlos Martín Briceño, Current Mexican narrative, Hybrid text.

Recibido: 13 de enero de 2020

Aceptado: 18 de julio de 2020 https://dx.doi.org/ I0.15174/rv.vi3i28.520

T a autobiografía ficticia, la novela autobiográfica y la autoficción conforman las tres posibilidades de las novelas del yo. Estas narraciones se aproximan -apunta Manuel Alberca-, de manera simultánea, a la autobiografía y a la novela, e introducen en la diégesis a un sujeto que funge como relator-protagonista de su historia, representación que el lector identifica por ciertos rasgos, ora textuales, ya paratextuales, con el escritor firmante en la portada del volumen; de tal modo, por moverse entre las inestables fronteras de la apariencia y la veracidad, entre el autor empírico 
(factualidad) y el narrador (ficcionalidad), estos textos escapan por igual al pacto autobiográfico y al pacto novelesco, para incardinarse en las paradojas y singularidades de la hibridez o del estatuto ambiguo (Alberca, 2012: 125-127).

De las tres posibilidades citadas nos interesa sondear la narrativa autoficcional, dado que es un género mestizo en el que sí es posible que un héroe lleve el mismo nombre que su autor; así, el pacto de ficción es compatible en novelas de esta clase y puede darse la identidad nominal entre autor, narrador y personaje (Casas, 2014: 9).

A finales de la década de los setenta y principios de los ochenta, como ha estudiado Ana Casas, la autoficción se ha practicado en el mundo hispánico desde distintas modalidades, a veces entremezcladas: intimista, biográfica, testimonial, humorística y autometaficcional. ${ }^{1}$ De acuerdo con Casas, en México la autoficción ha tenido como exponentes a Sergio Pitol, Margo Glanz, Angelina Muñiz-Huberman, Alejandro Rossi, Mario Bellatin, Julián Herbert y Guillermo Fadanelli (2014: 10-11). A esta nómina de narradores se han sumado Jorge Volpi, Guadalupe Nettel y, consideramos, Carlos Martín Briceño (1966).²

${ }^{1}$ A inicios de la década de los setenta del siglo pasado Arturo Souto llamaba la atención sobre la publicación, tanto en México como en el extranjero, de textos en los que se cultivaba la hibridez narrativa: "el ensayo viene a ser un puente entre la literatura de imaginación (que muchos consideran 'falsa') y las más auténticas y personales expresiones del escritor contemporáneo. Así, es frecuente encontrar en la actualidad prosas en las que el deslinde entre la fantasía o ficción y las vivencias concretas del poeta, es casi imposible" (1973: 43).

${ }^{2}$ Cristina Arreola Márquez considera la prosa autoficticia de Volpi en "Autoficción y dualidad en Jorge Volpi. Un acercamiento a su nouvelle $A$ pesar del oscuro silencio", en Interpretextos, 15, Primavera de 2016, pp. 29-41; Elisabeth Murcia estudia a Nettel en "Figura de autor e identidad marginal en El cuerpo en que nací, de Guadalupe Nettel”, en Diseminaciones, vol. 1, núm. 2, julio-diciembre de 2018, pp. 71-88. 
La muerte del Ruiseñor (2017) es una novela del yo que por sus características se arrima a la prosa autoficcional biográfica, es decir, al relato en el que el escritor, a través de su doble, es "el protagonista de su historia, el núcleo al cual se ordena la materia narrativa, pero imagina su existencia a partir de datos reales [...] lo más cerca posible de lo verosímil" (Colonna, 2012: 94); pero también, el relato de Carlos Martín Briceńo, al irse gestando frente a los ojos del lector, se aproxima a la narración con componentes metafictivos, ya que uno de los problemas "singulizadores" de este tipo de obras es, según Andrés Amorós, el "de escribir una novela, de un personaje que quiere escribir una novela... y al final comprendemos que su novela es la que hemos estado leyendo" (Orejas, 2003: 67).

La organización de la narración del yucateco, distribuida en treinta y ocho capítulos, se bifurca en tres perspectivas intercaladas a lo largo del texto: la primera, es la de un personaje narrador que comparte la misma identidad nominal del autor persona que firma el libro (el nombre propio, las iniciales del nombre y los apellidos, el apellido Martín del bisabuelo), que ha nacido y vive en la misma ciudad del novelista (Mérida, Yucatán), y que desde el presente de su escritura evoca su formación musical, escribe sobre su trabajo en una empresa y da cuenta de ciertos sucesos familiares, a modo de una veraz autobiografía; en el segundo plano narrativo, el mismo protagonista narrador devela sus fuentes documentales y reflexiona, frente a los ojos del lector, sobre el proceso personal y creativo de la novela que está escribiendo, que tiene como asunto a un músico meridano que es parte de la historia musical mexicana, en la variante del bolero; estas fracciones autoficticias y metafictivas ocupan un total de veintiún capítulos; por último, una tercera sección de diecisiete capítulos la constituye una fragmentada biografía ficcionada de un segundo protagonista llamado Guty Cárdenas, cantante y compositor de trova yucateca que triunfó en México y en Estados Unidos en las primeras décadas del xx: las cartas entre 
Guty y su madre, las dos secuencias donde se recrea su asesinato en un bar de la ciudad de México, las descripciones de la ascendente carrera del cantante, la relación con Rosita Madrigal -su última amante- y el monólogo narrado del padre de Guty.

Por el título y las imágenes plasmadas en las cubiertas de la obra, el lector cree que el peso del relato recaerá en el ámbito del cantante, pero a medida que avanza en la lectura descubre que las convergencias entre Guty Cárdenas, Carlos (novelista ficticio) y Carlos Martín Briceño (novelista empírico) se enraman, aunque sus historias respondan a temporalidades diferentes. Por tanto, en el mismo espacio novelesco se entrecruzan la autobiografía desdoblada, la metaficción y la biografía ficcionada. Por esta complejidad argumental, consideramos que La muerte del Ruiseñor revela caracteres propios de la auto-metanovela.

El yo empírico y el yo fabulado en una narración autometaficcional: La muerte del Ruiseñor

Uno de los motivos que dieron a la autoficción un lugar dentro de los estudios literarios fue la necesidad de acotar la esfera entre la autobiografía y la ficción (Alberca, 2014: 154). El carácter heterogéneo de la autoficción se sustenta en lo que Vincent Colonna denomina autoficción biográfica, es decir, que la sustancia que se ficcionaliza en el texto es la propia vida del autor real. Esta se conforma de experiencia empírica, la inserción del nombre propio y la mezcla intencionada de datos reales y verídicos con "relatos que bordean el estatuto de lo ficticio [y] de la elaboración fabulada" (Vásquez Rodríguez, 2014: 101), cualidades contenidas en la disposición de La muerte del Ruiseñor, y que son esbozadas desde la advertencia que el autor planta antes del primer capítulo: "La mayor parte de los hechos históricos, lugares, nombres, fechas, cartas, personajes y personas vivas y muertas que aparecen en esta novela 
son reales. Digo la mayor parte porque en muchas ocasiones están revestidos de una dosis de ficción” (Martín Briceño, 2017: 9). Así, queda anunciado que el escritor "no va a decir la verdad" (Alberca, 2012: 146) y que ensambla la veracidad con la verosimilitud, práctica en la que Carlos Martín Briceño defiende el estatuto genérico de novela para su creación y propone a la recepción lectora que no interprete la obra como una autobiografía o una biografía del compositor Augusto Cárdenas Pinelo. Esta idea se refuerza en la contraportada del libro: "Carlos Martín Briceño se convierte en personaje de su propia novela". Igualmente, Carlos, el narrador y protagonista, suscribe esta práctica al reconocer "que en la narrativa del nuevo siglo hay una tendencia cada vez más poderosa a borrar las diferencias entre la ficción y aquello que no lo es" (Martín Briceño, 2017: 152).

Tanto la advertencia preliminar a la narración como la afirmación de Carlos citada arriba encierran ecos de la definición, en apariencia contradictoria, que Serge Doubrovsky creó, en 1977, para la autoficción: "ficción de acontecimientos y de hechos estrictamente reales" (Alberca, 2007: 146-147). Deducimos que la autoficción es un relato que convida a los lectores a poner en juego sus dotes imaginarias, a desterrar la idea de que en las letras impresas solo se cuecen verdades.

En la autoficción biográfica "se abandonan la omisión o la codificación, se dan los apellidos, los patronímicos, los nombres de pila, el propio y el de los demás" (Colonna, 2012: 100); la identidad nominal, explícita o implícita, del narrador y/o protagonista coincidente con el autor de la obra, es uno de los puntales de la autoficción (Alberca, 2012: 145). En La muerte del Ruiseñor la homonimia no se camufla, sino que se formula en una charla del narrador con un amigo que lo nombra: “-Pero Carlos, ¿de veras vas a entrarle a eso? -me advierte el dramaturgo Eduardo Antonio Urcelay en el teléfono cuando le confieso que ya tengo la estructu- 
ra, el material biográfico, los personajes-" (Martín Briceño, 2017: 11). Más adelante, la voz ficcional reproduce una conversación por Facebook con un blogero, e inscribe sus iniciales "C.M.B." (2017: 31) que concuerdan con las del autor empírico. Además, el bisabuelo del autor protagonista se apellida Martín, como rememora en el apartado 33, designado "La acreditada Casa Martín".

Ahora bien, el enfoque autobiográfico que Martín Briceño elige para su narración encuentra asidero en una frase de Milan Kundera que Carlos cita al leerla en un café de Praga: “¿Acaso no es cierto que el autor no puede hablar más que de sí mismo?” (2017: 127). El héroe posee la clarividencia de que aún si continúa escribiendo sobre el cantante Guty, de todos modos se arrancará a hablar sobre su persona, como procede en varios tramos de su relato. Así, Carlos Martín Briceño, a través de su yo desdoblado, se lanza, como lo han realizado otros autores, "a la desafiante búsqueda de la verdad de sí mismo [bajo] el protector velo de la ficción” (Alberca, 2014: 154). Por esta razón, Henry Miller -a propósito de los matices autobiográficos contenidos en sus narraciones- puntualiza que "el hombre escribe para conocerse, y de este modo acaba desembarazándose de su yo. Tal es el objeto divino del arte" (Gros, 1976: 329). Esta frase nos ilustra la novela de Martín Briceño porque el autor ficcional hace un examen de conciencia, la recapitulación de una parcela de su vida, se despoja de tapujos y, a veces, se habla a sí mismo en sus líneas; el capítulo 10, "Confeso", es buen ejemplo de este fenómeno, incluso por el título que lo preside y por la segunda persona gramatical usada para decirse sobre ese hombre atropellado y muerto por él en la carretera, años atrás. Esta táctica narrativa permite al narrador hurgar dentro de su interioridad, hablarse a través de su propia palabra, por lo que dialoga con los mecanismos autoficticios doubrovskyanos, de orígenes psicoanalí- 
ticos. $^{3}$ Así, una vez que Carlos se conoce más se desprende de su yo y penetra en el círculo de los allegados: su padre, su madre, su mujer, sus hijos y sus amigos hasta delinear los contornos del otro, los del Ruiseñor yucateco.

Otros puntos que traman un parecido entre el protagonista narrador autoficticio con el escritor que rubrica la novela en la portada provienen de los elementos paratextuales analizados por Gérard Genette, tanto de peritextos (prólogos, dedicatorias, portada) como de epitextos (entrevistas, presentaciones, reseñas, críticas), estos últimos de naturaleza mediática y efímera (Arroyo Redondo, 2014: 67). De esta suerte, la información bio-bibliográfica contenida en la solapa del ejemplar dice que Carlos Martín Briceño nació en Mérida en 1966, y que antes de La muerte del Ruiseñor, su primera novela, ha ejercitado el género del cuento, predilección que queda manifiesta por los premios obtenidos en esta modalidad de escritura (uno de ellos obtenido en España), y por los títulos de sus libros de relatos publicados, de acuerdo con notas de prensa y de la solapa de Viaje al centro de las letras, por Ficticia Editorial, cuyo editor es Marcial Fernández, según consta en la página legal del volumen.

Carlos no ha publicado ninguna narración de alcances largos y es autor de varios tomos de relatos que han visto la luz en una editorial dirigida por su amigo Marcial Fernández, que es mencionado en la novela. Otra concurrencia entre persona y personaje es el caso del escritor Rafael Ramírez Heredia, que ha influido en el autor protagonista: a él "debo mi incursión seria en la República de las Letras" (Martín Briceño, 2017: 87), evento que concuerda con la experiencia literaria de Martín Briceño al asistir al taller im-

\footnotetext{
${ }^{3}$ Alberca comenta que Serge Doubrovsky razona su propia narración Fils, y afirma que "ha analizado los procedimientos escriturales puestos en juego por la novela, que el autor no entiende como escritura psicoanalítica ni del inconsciente, sino como escritura 'para el inconsciente"' (2007: 146).
} 
partido en Mérida por Ramírez Heredia, de quien aprendió a leer los textos desde otras configuraciones, como asegura en entrevistas y en Viaje al centro de las letras. Otro espejo literario entre C.M.B. y Carlos Martín Briceño es la intentona, sin resultado, por obtener la beca del Sistema Nacional de Creadores, como confiesa el narrador de la novela; prueba de que el autor empírico tampoco goza la beca, por lo menos hasta 2018, es que se trata de un dato no manifiesto en ningún mecanismo paratextual.

Asimismo, Carlos, el narrador textual, ha nacido en Mérida, evidencia la misma edad del autor empírico "cercano a los cincuenta” (Martín Briceño, 2017: 56), es gerente de "un gris corporativo" (2017: 56), en otros términos, es administrativo -como el autor de carne y hueso que estudió, según se declara en medios epitextuales, la licenciatura en Administración de Empresas (melissame, 2014)- , trabaja en una empresa (Montalván, 2014), y educa a dos chicos: "Esteban, mi hijo menor [...] Emilio, el primogénito" (Martín Briceño, 2017: 71), cuyos nombres coinciden con los de los hijos del escritor, conforme a una nota periodística en la que este conversa de "cómo le ha transmitido ese gusto [por la lectura] a sus hijos Emilio y Esteban Martín Medina” (Garma Montes de Oca, 2018), nombres que también figuran en la dedicatoria de la obra.

De igual manera, la mujer del héroe se dedica a la producción y a la actuación teatral, y por esos días de escritura de la novela trabaja en el montaje de una obra de contenido social sobre "la huelga interminable de una vieja empresa refresquera yucateca" (Martín Briceńo, 2017: 61), como la esposa del autor de La muerte del Ruiseñor, la actriz de teatro Ariadna Medina, fundadora del grupo Murmurante, que en 2014 produjo y actúo en Sidra Pino, puesta en escena sobre la prolongada huelga de los trabajadores de la misma marca de bebida local, información que puede corroborarse en la página web del grupo teatral y en el ofrecimiento que se hace a ella en esta novela "Para Ariadna, Emilio y Esteban", y en 
los agradecimientos incluidos en el texto "Un golpe de sol en los ojos", perteneciente al libro Viaje al centro de las Letras (2018): "a mi familia, especialmente a mi esposa Ariadna” (Martín Briceño, 2018: 84); por otro lado, el hermano que comparte aprendizajes musicales con el protagonista se llama Enrique, como corresponde en la esfera verdadera del autor, según detalla en sus apuntes autobiográficos "Un placer incomprendido", inserto en Viaje al centro de las Letras: "Entonces llegué a la adolescencia, y gracias al buen tino de mi hermano Enrique que comenzó a traer a casa los ejemplares de la Colección de Literatura Universal Bruguera” (2018: 67).

La música es también un lazo de corte autobiográfico entre el escritor y el autor inventado. En los dos asoma el gusto por las composiciones musicales vernáculas inculcadas por la familia, como queda de manifiesto en una entrevista que da el autor: "mi padre nos fomentó el gusto por el piano, por la guitarra" (Alba, 2018), y en la sección final de la novela "Agradecimientos", donde el autor recuerda a su tía Ligia Martín García por acercarlo a la guitarra; es el mismo caso de C.M.B. que reconoce a su padre por infundirle la música, y la narración de una juerga en La Habana ("La pura vida"), en la que acaba en un chalé cantando con una mujer melodías cubanas y yucatecas. No por nada, el epígrafe escogido para la novela es de Oscar Wilde: "El arte de la música es el que más cercano se halla de las lágrimas y los recuerdos".

Además, lo biográfico asoma en el capítulo 24, titulado "De vuelta a la Negrita" -en la que el autor rememora una tarde de sábado a mediodía al lado de su padre que bebe unos tragos en la cantina nombrada-, pues es trasplantado con el mismo marbete en la sección autobiográfica "Cabos sueltos" del libro de crónicas, ensayos y memorias Viaje al centro de las letras.

Aun así, no se puede tildar con contundencia de autobiografía a La muerte del Ruiseñor, y aunque existan elementos que dan la 
impresión de pertenecer a una construcción del yo más íntimo y personal, hasta en ellos se filtra la ficción que trastoca la verdad y la desliza hacia "el juego y la simulación engañosa de la autoficción" (Alberca, 2012: 148): los premios en España y la muerte del padre.

Carlos sostiene en un soliloquio que cuenta con un "par de premios que recibí en España” (Martín Briceño, 2017: 100), pero esta circunstancia no se ve duplicada en la carrera literaria del autor de carne y hueso: tanto en las solapas de la novela como de su último volumen publicado en 2018 (Viaje al centro de las letras) no se da a conocer más que un único galardón, el Premio Internacional de Cuento Max Aub (2012), convocado en España.

Pero es el segundo punto el que nos parece más interesante por la irrupción de lo inventivo, que da a La muerte del Ruiseñor su cualidad autoficticia. Un sensibilizado Carlos -acaso porque él también estuvo en un hospital a punto de la extinción- describe en varios espacios textuales de la novela la agonía y muerte de su padre, a quien está agradecido por codearlo, desde la infancia, con la música vernácula; por tanto, le dedica la novela, como se aprecia en el homenaje inicial del libro y en la última frase del mismo: "a la memoria de mi padre" (2017: 196). Mas en la vida auténtica de Carlos Martín Briceño la desaparición física de su antecesor es un hecho no acaecido cuando se edita su obra, como comprobamos en dos paratextos. En Viaje al centro de las letras comenta en el apartado "Breve repaso de lo bailado" que, a causa del tiempo transcurrido, ha perdido virtudes para el baile, y "ahora que mi padre es mayor, sobrepaso los cincuenta y ni siquiera los pilates me han servido para recobrar mi agilidad de antaño" (2018: 54). A esto se suma la afirmación inserta en un artículo publicado un año después del libro citado con anterioridad: "recordé que durante mucho tiempo, mi padre, cuya vida se agota, tuvo en su buró el libro..." (Martín Briceño, 2019). De este modo, confirmamos que el deceso del progenitor de Martín Briceño no ha sucedido en 
el año de publicación de la novela (2017), por consiguiente, este incidente pertenece a la fabulación.

La autobiografía siempre ha sido una tentación en el quehacer literario de Carlos Martín Briceño. Lo confiesa en las páginas de corte factual alojadas en "Cabos sueltos":

Más tarde, cuando decidí incursionar en el mundo de las letras [...] intenté narrar una especie de memorias tempranas [...] Nunca las terminé: para mi buena fortuna se cruzó en mi camino el taller de narrativa de Agustín Monsreal, donde aprendí que en literatura más vale cuento en mano que novela volando. Me hice cuentista y abandoné la empresa de escribir aquella pretenciosa autobiografía (2018: 55).

La salida al prurito por la escritura en primera persona del autor yucateco ha sido la confección de una prosa con tintes autoficticios, narración en la que puede volcar y entreverar factualidad con verosimilitud. El escritor no pretende escribir una autobiografía a la usanza tradicional, sino pedazos significativos de su temporalidad pretérita, incluso sin respetar la cronología, y en esto se nota que "la autoficción tiende a mostrar al escritor en su inagotable proceso de invención; es decir, en su tarea de construirse una identidad inevitablemente segmentada dentro de su propio texto" (Arroyo Redondo, 2011: 88), una identidad que puede hablarse sobre su pasado como gerente, su infortunado primer matrimonio, su divorcio, el atropellamiento de un anciano, los errores con sus descendientes.

La evocación del vivir de Carlos Martín Briceño, a través de su yo ficticio, lo pone a él mismo como héroe o protagonista de su historia; de esta guisa, el escritor autoficticio "fabula su existencia real a partir de datos que le identifican" (Alberca, 2007: 182-183), pero no se queda en el puro egotismo, ya que es capaz de dilatarse 
más allá de sí mismo para tornarse en mirada reflexiva y crítica hacia los procedimientos creativos y los sinsabores del oficio literario. Estamos ante una prosa auto-metaficcional, ante la autoconciencia de la problemática vivencial empalmada a la espinosa tarea de armar una novela sobre un trovador olvidado.

A finales de la década de los ochenta Gonzalo Sobejano especuló sobre la novela que desde hacía algunos años se escribía en España, y destaca a la metanovela como una de las tendencias escriturales. La define como una novela que no solo refiere a un mundo representado sino que se refiere a sí misma, en gran proporción o principalmente, ostentando su condición de artificio (1989: 4); a su vez, destaca tres categorías de la metanovela: de la escritura, de la lectura y del discurso oral. Por considerar que La muerte del Ruiseñor acusa características que emparentan con la metanovela de la escritura, nos enfocaremos en esta modalidad en la que el autor fictivo dirige su atención no sólo al mundo representado, sino al proceso de ir creándolo mediante la reflexión y la realización de sus partes. Es el tipo de narrador consciente de sí mismo como escritor, que se da cuenta que está escribiendo, pensando, hablando o "reflejando" una obra literaria (Booth, 1978: 147).

La conciencia reflexiva del héroe de Martín Briceño se vuelca hacia tres tipos de cavilaciones: las que abordan los pensares sobre la novela que está escribiendo; las que discurren sobre el cuento, la novela y sus técnicas creativas; por último, las que fluyen sobre las dificultades y sinsabores de un escritor no profesional como él. En los párrafos siguientes nos abocaremos a sondear estas bifurcaciones metanovelescas.

Ya en las primeras páginas de La muerte del Ruiseñor el narrador expone los tres ingredientes que posee para configurar su texto: tres libros sobre el artista yucateco que ha recopilado, varias referencias bajadas de internet, su imaginación. Más adelante transcribe párrafos - con la autorización del autor contactado por Facebook-de 
una entrevista-recuerdo de don Roberto, el mesero que asistió a Guty en los últimos instantes de su vida, publicada en un blog en 2010; asimismo, da a conocer una lista de documentos consultados, que pone a su disposición el director del Centro Regional de Investigación Musical del Estado de Yucatán: Cancionero Picot, cartas del padre de Guty a su hija lamentando el asesinato, fotos, catálogos, partituras originales de algunas canciones de Cárdenas Pinelo, e incluye la letra de "La República en España”, aquel "mítico corrido que pudo haber ocasionado la muerte del trovador" (Martín Briceño, 2017: 144). Estos materiales servirán a Carlos para "armar una novela sobre este trovador que, fuera del ámbito de la hermana República Yucateca, hoy pocos recuerdan; una nouvelle que, además, me ayude a incursionar en serio en el caprichoso mercado de la industria editorial" (2017: 13). Tampoco el yo ficticio oculta a los ojos de los lectores el germen de su novela, a la que en un par de ocasiones tilda de "histórica": la invitación del editor de Ficticia para escribir un cuento para una antología sobre la ciudad de México. En respuesta, entregó un relato sobre el asesinato de Guty Cárdenas, ocurrido en el Salón Bach, ubicado en la céntrica calle Madero. Igualmente, comparte posibles títulos que baraja para su futura obra, como nombres de canciones del propio Guty: "Necesitaba terminar Como un rayo de sol, Presentimiento o como fuera a titularse mi novela" (2017: 56).

La obra se va fraguando sin prisa pero sin pausa, a veces se ha visto interrumpida pero es una ficción que va tomando cuerpo a deshoras, como transparenta el relator: "pergeńo en la quietud de la madrugada un capítulo más de esta novela" (Martín Briceño, 2017: 71); él desea "crear un texto entrańable, una historia que permanezca largo tiempo rebotando en las mentes y corazones de los lectores" (2017: 65), alejada de las prosas facilonas, como las del espańol Posteguillo, capaces "de atraer la atención de cualquiera” (2017: 64) gracias al "tramposo manejo del suspense" (2017: 
65) y al uso de la incertidumbre, como en las series americanas, para despertar la curiosidad del lector. Mediante estas develaciones, la creación de Martín Briceño es ficción autorreferencial: habla de sí misma y de cómo se está escribiendo, dicho de otra forma, "lleva de manera recurrente en sus líneas tanto la invención como la reflexión sobre ella, el acto de narrar y la exploración de sus resortes" (Lluís Izquierdo, 1997: Xvi), un ejemplo metaficcional que se nutre de literatura y de otros intertextos culturales, como el de la trova yucateca.

La muerte del Ruiseñor se arregla con disquisiciones escriturales que se suman a las confesiones literarias que el autor vuelca sobre su quehacer artístico (Aubry, 2019: 77), de tal modo que el autor ficcional visibiliza sus contenciones argumentales, como en el caso de la supuesta rivalidad entre Agustín Lara y Guty, anécdota que nutrió la posibilidad de que Lara haya mandado a los hermanos Peláez a darle escarmiento al yucateco, pero el narrador reconoce que no quiso sazonar con ficción el supuesto encono, por parecerle excesivo maquinar a Lara como un gánster receloso. Ante las lagunas con las que se ha topado para ilustrar ciertos sucesos sobre Guty, el autor personaje autoconsciente externa sus trances en la fase constructiva, y no le queda más remedio que suplir la carencia con suposiciones. En este caso, Carlos Martín Briceño es un fabulador que ha tenido que echar mano de la imaginación cuando la referencialidad destapa vacíos.

Otros apuros enfrentados por el autor protagonista provienen de su devoción por la prosa breve; mientras informa sobre el progreso de su escritura sobre el compositor, también reflexiona sobre el arte del cuento y su fervor por el género: "he abandonado esta novela momentáneamente. Llevo varias semanas sin escribir una sola línea. Me he dedicado a inventar nuevos relatos" (Martín Briceño, 2017: 119), y examina el contenido de uno de ellos, un asesinato consumado en un cibercafé de Mérida. Por eso, se cues- 
tiona: “¿Será que defiendo tanto al género por temor a errar en la novela?” (2017: 122), y expone los orígenes de sus propios cuentos que "surgen de la cotidianeidad, de las relaciones de pareja, del horror al tedio, de ese mensaje universal que es el sexo, de situaciones anómalas dentro de vidas aparentemente tranquilas" (2017: 153). Además, confiesa que pasajes de una novela fallida acabaron transformados en cuentos.

El yo narrativo se afianza en su credo profesional por el relato, pese a las admoniciones de su mujer, quien le sugiere que una novela histórica es lo que lo conducirá a la fama, que eso reclaman los lectores, no la publicación de textos breves; pero él insiste, busca inspiración en los maestros (Mario Vargas Llosa, Javier Marías, Raymond Carver), y llega a conclusiones: "el cuento [...] es un golpe de sol en los ojos del lector, un paseo por las entrañas de la condición humana” (2017: 121-122).

La muerte del Ruiseñor narra cómo un cuentista pasó al ámbito del novelista, pero también describe las dificultades de un escritor que dedica poco tiempo a la literatura por trabajar muchas horas en una empresa, para mantener a su mujer y a sus dos hijos. Este tono confesional sostenido por la instancia productora del discurso en su papel de esposo y padre alberga el desaliento por la profesión: la desilusión por no ganar concursos literarios y por los intentos fallidos de ingresar al Sistema Nacional de Creadores. Este tipo de confidencias suelen ser frecuentes en las metanovelas.

Toda metanovela -observa Carlos Javier García- contiene el recurso de un personaje escritor reflexivo que notifica sobre los avatares de la vida a la vez que transmite la historia de la composición, "tocándose aspectos variados, desde la invención o copia de situaciones y personajes, hasta aspectos tocantes a la narración y las revelaciones de personajes de la escritura" (2006: 70); en este sentido, La muerte del Ruiseñor participa de las cualidades de la metanovela, pero se nutre de un par de componentes que le otor- 
gan sus propias señas de identidad: en primer término, el autor ficticio luce un nombre coincidente al del escritor que suscribe el relato; en segundo lugar, las afirmaciones transmitidas por el autor inventado no solo son cavilaciones sobre su arte y la recreación del Ruiseñor yucateco, sino acotaciones que planean sobre su propio yo, que orbitan sobre su existencia cotidiana y familiar, y que llegan a integrar varios capítulos o a inmiscuirse con más asuntos en otros apartados. Estas consideraciones guían nuestra interpretación y nuestra propuesta de una lectura bajo los lineamientos de la auto-metanovela para la primera obra de aliento largo de Martín Briceño.

La irrupción de la autoficción en la narrativa española ocasionó que los novelistas desistieran de novelar para caer en el vicio de enredarse en la problemática del escritor que se ve escribir y se olvida de los problemas de la realidad circundante. Es la percepción de algunos críticos, entre ellos Anna Caballé, quien refiere: "al novelista ya no le fue necesario inventarse un mundo imaginario, unos personajes, un paisaje [...] Le basta con recrearse a sí mismo (y a sus seres próximos, igualmente gentrificados) instalándose en el eje de la acción como único paisaje posible" (2017). Esta tendencia solipsista padecida por la novelística espańola contemporánea es de cierta manera librada en La muerte del Ruiseñor por Carlos Martín Briceńo, quien salva el narcisismo y la autocomplacencia de exponer sus preocupaciones metaliterarias, de mirarse a sí mismo y a sus cercanos, y amplía los horizontes del lector al alternar los reflectores de la narración hacia el otro, hacia un segundo protagonista de la trama: Guty Cárdenas, cantautor y paisano suyo que, incluso, aporta el rótulo de la novela. 


\section{El otro protagonista: ni "cantante del montón" ni "trovador fracasado"}

Un tercer enfoque narrativo introducido en La muerte del Ruiseñor se concentra en los pinitos artísticos de Augusto Alejandro Cárdenas Pinelo -mejor conocido en el mundo musical como Guty Cárdenas-, su ascenso en las compañías disqueras norteamericanas y su trunca existencia a los veintiséis ańos. De esta suerte, la temporalización que abarca la historia de Guty comprende siete años, de abril de 1925 -fecha de la introspección del padre de Guty-al cinco de abril de 1932, día del crimen.

En La muerte del Ruiseñor asistimos a la evolución de un cantante y compositor que logra fama en el medio de la época, trazos narrativos que nos llevan a pensar en la relatoría parcial de la existencia del trovador meridano, o en lo que el propio autor de cuentos metamorfoseado en novelista califica como "la biografía novelada de Guty" (Martín Briceño, 2017: 11). El adjetivo "novelada" de esta parcial "biografía" se sustenta en las estrategias discursivas ostentadas por el autor ficcional: recreación de cartas, como las de Guty a su madre; desarrollo de párrafos en omnisciencia neutral y selectiva; empleo de monólogo interior y narrado. Estas comunicaciones son interpuestas en diversos segmentos de la trama.

Cuatro son los capítulos en los que se reproducen cartas que Guty dirige a su madre, fechadas en Mérida, Nueva York, Hollywood y Veracruz. En estas correspondencias el personaje es un enunciador con función doble: presentarse a sí mismo al contar lo que hace, piensa y siente, así como enterarnos de su clamorosa andadura como cantante. Desde la primera misiva se advierte su pasión por la música -a pesar de los empeños de su padre por alejarlo de ella-, y en las siguientes cartas sabemos de las canciones que graba, las disqueras y las personas que lo rodean en sus actuaciones. En la carta desde Nueva York cita los buenos comentarios que 
la prensa le dedica y reconoce el apoyo de su progenitora para la carrera artística; por eso encarga a esta, en un franco revanchismo, que diga a su padre "que su hijo no se convirtió en un cantante del montón, en un trovador fracasado como él auguraba” (2017: 97). La carta proveniente de Hollywood proporciona noticias notables: la invitación del presidente Hoover para que actúe en la Casa Blanca y la promesa de convidar a su madre.

A la par, el narrador cuenta, desde la objetividad de la omnisciencia neutral, secuencias de la vida de Guty, con diversos escenarios de fondo: Mérida, Ciudad del Carmen, Hollywood, La Habana, un barco rumbo a Nueva York; pero también utiliza técnicas que le permiten relatar desde la interioridad de los personajes, como la reproducción del espacio subjetivo del padre de Guty en el café, inserta en el capítulo 9: "Una greca directa". La importancia del apartado reside en exhibir al oponente del héroe mediante el monólogo narrado o estilo indirecto libre:

Por supuesto que no estaba de acuerdo. ¿Cómo iba a estarlo? Una cosa, decía, era enseñar a tus hijos a amar la música como cualquier yucateco de buena familia, y otra, muy diferente, que alguno saliera con su domingo siete [...] ¡Así que músico! ¿De qué coño piensa este muchacho que va a vivir? [...] A partir de ahora haría todo cuanto estuviese en sus manos para que Guty olvidara esa locura de vivir de la trova (Martín Briceño, 2017: 37-41).

En la situación comunicativa citada se funden las voces del narrador y la del padre de Guty, es decir, aparecen señales de ambos hablantes: la tercera persona gramatical alude al acto enunciativo del narrador, pero la evaluación de la realidad y el léxico usado pertenecen al personaje, la forma usual del discurso indirecto libre (Filinich, 1997: 165-166). 
Asimismo, a través de la omnisciencia selectiva podemos rastrear las intromisiones del narrador en la estructura mental de ciertos personajes. En el capítulo 36, titulado “Ojos verdes”-además de párrafos en voz omnisciente y de otros en monólogo narrado, pues están elaborados por Rosita Madrigal- Guty es observado y narrado por una voz omnisciente selectiva que ha elegido relatar desde la perspectiva de la amante del cantante, un ojo avizor:

Sus dedos, largos y ágiles, se deslizaban con tal destreza y suavidad por el mástil de la guitarra que [...] cerró los ojos e imaginó lo que sentiría si esas manos recorrieran con la misma habilidad su cuerpo desnudo. Y qué decir de su energía. Cada vez que el compositor jalaba aire para entonar las primeras estrofas de una nueva canción, Rosita sentía que una tenue corriente de electricidad le recorría por entero la piel [...] Así que cuando se enteró de que el yucateco había sido invitado por la XEw a encabezar el elenco [...] se propuso conquistarlo. Poco le importó que el compositor estuviera a punto de casarse con una gringa insípida e insulsa que, seguramente, "no será mejor que yo en la cama" (2017: 180-181).

Estos artilugios narrativos permiten al novelista "representar desde dentro los pensamientos y procesos psicológicos" de los entes históricos-ficticios (Alberca, 2012: 138-139), y se repiten en los capítulos 3 y 37, titulados Salón Bach (I) y Salón Bach (II), respectivamente; estas divisiones son privilegiadas por tratarse del sitio donde ocurre el entrecruzamiento de Eros y Tánatos: allí se conciertan, desde distintos ángulos, las últimas vivencias y los detalles de la muerte del Ruiseñor.

Salón Bach (I) acusa complejidad narrativa, ya que el relato se fragmenta en varios registros discursivos, que se van intercalando: la omnisciencia neutral, la omnisciencia selectiva y el monólogo narrado, estos dos últimos bajo la voz y el punto de vista del mese- 
ro Roberto Miranda, quien cumple con las funciones de relatar(se) -tanto escenas del pasado inmediato como del presente dentro de la cantina- y de focalizar -cual cámara cinematográfica- a los participantes en la juerga que transcurre frente a sí hasta desembocar en el desenlace trágico: los disparos, los cuerpos caídos, los momentos postreros del cantante.

Salón Bach (II) se construye a través de la técnica del monólogo interior, o sea, es la recreación en cinco páginas del flujo de conciencia del moribundo Guty tendido en el piso del bar, una "progresiva desarticulación del discurso [que] muestra el carácter fragmentario y contradictorio de la experiencia perceptiva [...] en un tiempo presente" (Filinich, 1997: 128-134). Por la cada vez más nublada conciencia de Guty se van sucediendo ideas -separadas por comas- acerca de lo que acaba de pasarle en la cantina con los hermanos Peláez, sobre su malograda carrera, sobre figuraciones de mujeres amadas, pero también fluyen recuerdos de su pasado y de los suyos en su ciudad natal:

[...] coño, ¡qué dolor!, ¿cómo chingados fue a sucederme esto?, justo cuando estoy por terminar nuevas canciones con el Mediz Bolio [...] "tú y yo podemos componer un estilo de canción que tenga el aliento de nuestra tierra”, pobre, quería montar un ballet con mis melodías para recorrer el mundo [...] se me llena la cabeza de recuerdos, la imagen de la casa donde nací, el patio central con sus helechos, malangas y buganvilias [...] el parque arbolado de Santa Lucía, los rostros de mis hermanitos Renán y Raúl [...] el azul intenso del mar yucateco [...] las manos blancas de mi madre [...] el cuerpo frágil, pequeño, desnudo de mi esposa Ana, los pechos generosos de Nancy Torres [...] ay, Rosita, Nancy, Ana (Martín Briceño, 2017: 190-191). 
Esta tercera posibilidad lectora de La muerte del Ruiseñor nos lleva a preguntarnos por las razones de Carlos Martín Briceńo -novelista de carne y hueso- y Carlos - novelista ficcional- para escoger como materia narrativa la vida y muerte de Guty; recurrimos a las homologías y a la identificación que ambos Carlos sienten por este otro protagonista, también nacido en Mérida. Empezaremos por remarcar los estudios profesionales del autor, del narrador personaje y del protagonista. Martín Briceño cursó administración de empresas y es gerente de Fundación Bepensa (según página web de la organización que pertenece a la industria mexicana de Coca Cola); Carlos adquiere "formación administrativa" (2017: 120) y es gerente de un corporativo; Guty se graduó de contador y su primer trabajo fue en Casa Pinelo, tienda-almacén que su padre piensa heredarle -como primogénito- para que administre. Otra axial coincidencia proviene de las actitudes paternales que no consienten las vocaciones elegidas por los vástagos, que son instigados a estudiar carreras boyantes; la situación del autor empírico es la de un padre "que no quería que yo fuera escritor" (Alba, 2018), la del narrador es haber tenido un ascendiente que "nunca me alentó a dedicarme a las letras" (Martín Briceño, 2017: 87), y la de Guty uno que no lo quiere de cantante, sino dedicado a la carrera comercial.

La música de la península es ligazón entre el autor, el narrador protagonista y Guty. En los dos primeros asoma el apego a las composiciones musicales domésticas inculcadas por la estirpe, como hemos observado; en consonancia, a Guty "le emociona promover la canción yucateca en otras latitudes" (2017: 171), por eso pretendía musicalizar el libro La tierra del faisán y del venado, de su coterráneo Mediz Bolio. Tampoco obviamos un par de coincidencias entretejidas en torno a la relación entre Carlos y Guty: así como el padre de Guty funda su acreditada Casa Pinelo, don Rudesindo Martín, el bisabuelo de Carlos, inauguró en Mérida, 
a fines del xix, la Casa Martín, la vendedora de los primeros fonógrafos y el primer comercio que distribuyó en la península los discos Columbia, la casa disquera de Guty; pero, además, el narrador cae en cuenta que la casa de Guty quedaba muy cerca de Casa Martín:

Guty nació en 1905; el auge del almacén de mi bisabuelo se dio entre 1890 y 1920 . Estoy seguro de que Guty, siendo niño, tuvo que haber pasado infinidad de veces ante sus puertas. Me lo imagino deteniéndose frente a los gramófonos para escuchar, azorado, las óperas y las zarzuelas que emanaban de los discos de moda (2017: 166).

Una curiosa relación más se entabla entre el narrador ficcional y Guty: la duplicación. Carlos acepta el proyecto de un supuesto empresario para figurar como Guty Cárdenas en el acto inaugural del restaurado Salón Bach, en la ciudad de México, como se lo cuenta a su mujer en el capítulo "Llámenme Ismael": "Sabe que toco la guitarra y quiere que esa noche cante y haga el papel del trovador. Incluso debo morir en el escenario" (2017: 100). Por el apresamiento del falso hombre de negocios, nunca se llevó a la práctica el espectáculo de la suplantación, la de Carlos convertido en Guty.

Por último, nos parece interesante el paralelismo entre Carlos Martín y Guty ante la cercanía de la muerte. El escritor en peligro por la intoxicación causada por picaduras de hormigas lamenta el fin de su vida; se dice en el hospital: “¿Qué manera tan estúpida de morir! ¡Peor que la de Guty!” (2017: 54); el Ruiseñor se habla mientras agoniza: “iqué manera tan vulgar de decirle adiós al mundo!, ¡mejor morir en La Chicharra acompañando al general Serrano!" (2017: 189). Asimismo, ambos protagonistas se inquietan por los titulares de la prensa que anunciarán sus defunciones; 
Carlos lo diseña así: "Conocido escritor yucateco, autor de varios libros de relatos, fallece a causa de un choque anafiláctico originado por las picaduras de una docena de hormigas rojas. Patético. Dos o tres líneas cuando mucho" (2017: 56); Guty imagina "los encabezados en la prensa de mañana, ¡ $\mathrm{Ha}$ muerto! El Ruiseñor yucateco, el cantor que llegó al alma del pueblo falleció en una riña cantinera', carajo" (2017: 189). Los lamentos de los protagonistas son por la discontinuidad de sus carreras y proyectos: una primera novela inacabada, unos amputados propósitos musicales.

Las incertidumbres del autor textual se ven reflejadas en las dudas por la publicación futura de su obra, que sí vio la luz pública, como constata el lector al asirla: "Si algún día la termino, si decido a publicarla, esta nouvelle debe de convertirse en un sencillo homenaje al hombre que me acercó a los boleros [...] y a las canciones yucatecas" (Martín Briceño, 2017: 196). Estas vacilaciones del autor ficticio sobre lo llamativo de la tematización de La muerte del Ruiseñor se corresponden con la voluntad de Carlos Martín Briceño de escribir sobre un tema que no está de moda, que no es patrocinado por el mercado editorial y que se aparta de la práctica del novelar mexicano actual; en su escritura, Martín Briceño huye de la inautenticidad, de la ola de lo kitsch, y, como comenta Uslar Pietri a partir de las consideraciones de Broch y de Kundera sobre la lucha de la novela moderna, no cae en lo consentido o en "la actitud de los que se proponen agradar al mayor número posible y que los lleva a repetir y aceptar lo que todo el mundo repite y lo que todo el mundo quiere oír" (1985: 1), escribir o leer, agregamos a la reflexión uslarpietriana.

Los elementos compositivos de La muerte del Ruiseñor reflejan su hibridez textual. En el mismo espacio narrativo coexisten: un escritor que - postuló Colonna- fantasea una personalidad y una existencia, manteniendo su identidad real (Alberca, 2007: 152), en otras palabras, estamos ante el texto de un escritor que es y no es; 
un autor imaginado, de nombre coincidente con el escritor real, que exterioriza su problematicidad íntima y elucubra en torno al género narrativo y a la novela que lo ocupa sobre la trayectoria y los últimos momentos de vida de Guty Cárdenas. Estas disímiles focalizaciones se interrelacionan en la mayoría de las secuencias narrativas, y nos afianzan en estimar a La muerte del Ruiseñor como una ficción escrita bajo estrategias auto-metanovelescas.

\section{Bibliografía}

Alba, Pilar, 2018, "Carlos Martín Briceño. La muerte del ruiseñor y el arte de escribir cuentos", La Jornada Zacatecas, 20 de agosto. Disponible en: http://ljz.mx/2018/08/20/carlos-martin-briceno-la-muerte-del-ruisenor-y-el-arte-de-escribir-cuentos/

Alberca, Manuel, 2007, El pacto ambiguo. De la novela autobiográfica a la autoficción, Biblioteca Nueva, Madrid.

, 2012, "Las novelas del yo", en La autoficción. Reflexiones teóricas, Ana Casas (comp.), Arco / Libros, Madrid, pp. 123-149.

, 2014, "De la autoficción a la antificción. Una reflexión sobre la autobiografía española actual", en El yo fabulado. Nuevas aproximaciones criticas a la autoficción, Ana Casas (ed.), Iberoamericana / Vervuert, Madrid / Frankfurt, pp. 149-168.

Arroyo Redondo, Susana, 2011, La autoficción: entre la biografía y el ensayo biográfico. Limites del género, tesis de Doctorado, Universidad de Alcalá.

, 2014, "El diálogo paratextual de la autoficción", en El yo fabulado. Nuevas aproximaciones criticas a la autoficción, Ana Casas (ed.), Iberoamericana / Vervuert, Madrid / Frankfurt, pp. 65-77. 
Aubry, Kenia, 2019, "La muerte del Ruiseñor, de Carlos Martín Briceńo”, Casa del tiempo, vol. V, núm. 59, noviembre-diciembre, pp. 76-77.

Booth, Waine C.,1978, “Tipos de narración”, en La retórica de la ficción, Santiago Gubern Garriga (trad.), Boch Editor, Barcelona, pp. 141-157.

Caballé, Anna, 2017, “¿Cansados del yo?”, Babelia de El País, 6 de enero. Disponible en: https:/elpaís.com/cultura/2017/01/06/ babelia/1483708694_145058.html

Colonna, Vincent, 2012, "Cuatro propuestas y tres deserciones. (Tipologías de la autoficción)”, en La autoficción. Reflexiones teóricas, Ana Casas (comp.), Arco / Libros, Madrid, pp. 85-122.

Casas, Ana, 2014, "La autoficción en los estudios hispánicos: perspectivas actuales", en El yo fabulado. Nuevas aproximaciones críticas a la autoficción, Ana Casas (ed.), Iberoamericana / Vervuert, Madrid / Frankfurt, pp. 7-21.

Filinich, María Isabel, 1997, La voz y la mirada. Teoría y análisis de la enunciación literaria, Plaza y Valdés Editores / Benemérita Universidad Autónoma de Puebla, México.

García, Carlos Javier, 2006, "Metanovela y teoría de la novela: una conexión interrrogativa de la autorreflexividad”, Anthropos, $\mathrm{Me}$ taliteratura y metaficción, núm. 208, pp. 65-70.

Garma Montes de Oca, Patricia, 2018, "Carlos Martín se torna un Julio Verne de papel”, Diario de Yucatán, 30 de noviembre. Disponible en: https://www.yucatan.com.mx/imagen/carlosmartin-se-torna-un-julio-verne-de-papel

Gros, Bernard, 1976, La literatura: desde el simbolismo al nouveau roman, Juan José Ferrero (trad.), Ediciones Mensajero, Bilbao.

Izquierdo, Lluís, 1997, "Introducción”, en El cuarto de atrás, de Carmen Martín Gaite, Ediciones Destino, Barcelona, pp. IIIXLVIII. 
Martín Briceño, Carlos, 2017, La muerte del Ruiseñor, Ediciones B, México.

, 2018, Viaje al centro de las letras, Ficticia Editorial / Secretaría de la Cultura y las Artes de Yucatán, México.

, 2019, "Para decir gracias o de cómo me hice escritor", La Jornada Maya, 1 de agosto. Disponible en: https://www.lajornadamaya.mx/2019-08-01/Para-decir-gracias-o-de-como-mehice-escritor

[melissaME], 2014, "Entrevista con Carlos Martín Briceño, escritor yucateco (primera parte)", El Altavoz, 4 de febrero. Disponible en: http://elaltavoz.mx/2014/02/04/entrevista-concarlos-martin-briceno-escritor-yucateco-primera-parte/

Montalván, Eugenia, 2014, "Entrevista con Carlos Martín Briceño", Tierra Adentro, enero. Disponible en: https:/www.tierraadentro.cultura.gob.mx/entrevista-con-carlos-marin-briceno

Orejas, Francisco G., 2003, La metaficción en la novela española contemporánea, Arco / Libros, Madrid.

Sobejano, Gonzalo, 1989, "Novela y metanovela en España”, Ínsula, núms. 512-513, agosto-septiembre, pp. 4-6.

Souto, Arturo, 1973, El ensayo, Asociación Nacional de Universidades e Institutos de Enseñanza Superior, México.

Uslar Pietri, Arturo (1985). "La risa de Dios", en el suplemento cultural del Diario de Yucatán, 7 de julio, p. 1. Vásquez Rodríguez, Gilberto D., 2014, "Condición de verdad y ficción. (Literaturas del recuerdo y autoficción)", en El yo fabulado. Nuevas aproximaciones criticas a la autoficción, Ana Casas (ed.), Iberoamericana / Vervuert, Madrid / Frankfurt, pp. 79-105. 